\title{
Analysis of the effects of mineral fertilization on species diversity and yield of permanent grasslands: revisited data to mediate economic and environmental needs
}

\author{
M. Kizekova ${ }^{1}$, E. Feoli ${ }^{2,5}$, G. Parente ${ }^{3}$ and R. Kanianska ${ }^{4}$ \\ ${ }^{1}$ National Agricultural and Food Centre - Grassland and Mountain Agriculture Research Institute, Mládežnícka 36, \\ 97421 Banská Bystrica, Slovakia \\ ${ }^{2}$ Department of Life Sciences, University of Trieste, Via A. Valerio 10, 34100 Italy \\ ${ }^{3}$ Honorary Life President, European Grassland Federation, Via Adamello 27, 33078 San Vito al Tagl.to (Pordenone), \\ Italy \\ ${ }^{4}$ Matej Bel University Banská Bystrica, Faculty of Natural Sciences, Tajovského 40, 97401 Banská Bystrica, Slovakia \\ ${ }^{5}$ Corresponding author.Email: feoli@units.it
}

Keywords: Cluster analysis, Similarity theory, Sustainable development, Trade-off.

\begin{abstract}
The 2013 reform of the European Common Agricultural Policy tries to support farmers willing to follow environment-friendly rural practices, by the so called "green payment". Within this framework, it is suggested that governments and regions should maintain a certain ratio of the area of permanent grasslands to the total Utilized Agricultural Area according to the greening rules of the reform. However, the weak economic performance of permanent grasslands does not encourage farmers to invest into their conservation. This fact persuaded us to revisit our old unpublished data, obtained by experiments on the use of chemical fertilizers in permanent grasslands. By this reanalysis we hope to further support the new European policy with the perspective to find a trade-off between the conservation of the biodiversity and the economic productivity of permanent grasslands. Of the many possibilities we have chosen to present the results of two experiments, one in Italy and the other in Slovakia. The main reason for this choice was that these two studies followed complementary strategies of fertilization that appeared useful to detect both the single and the synergistic effects of N, P, and K on the relationships between yield and species diversity. The results of cluster and diversity analysis suggest that chemical fertilization should be carefully planned according to soil conditions, since different treatments may have the same effect on the floristic and vegetation patterns of grasslands. These results, according to similarity theory, allow to choose the least expensive and polluting combination of $\mathrm{N}, \mathrm{P}$ and $\mathrm{K}$ from those that, according to the species combinations, are assigned to the same cluster.
\end{abstract}

Abbreviations: CAP - Common Agricultural Policy; IT - Italy; NPK - Nitrogen; Phosphorus and Potassium; SK - Slovakia; UAA - Utilized Agricultural Area; VU - Vegetation Units.

Nomenclature: Pignatti (1982).

\section{Introduction}

In Europe, the conversion of permanent grasslands of flat lands and/or gentle slopes into arable lands and their abandonment or afforestation in the majority of mountain areas are consequences of their weak economic performance (Habel et al. 2013, Dengler et al. 2014). However, permanent grasslands below and beyond the tree line should still have relevance in the perspective of the so-called new "green economy” dedicated to sustainable development (Nábrádi 2004, Kemp et al. 2013, Jean-Vasile et al. 2013). There is no doubt that besides their role in preserving plant diversity (Hobbs and Huenneke 1992, Härdtle et al. 2006, Poldini et al. 2011, Gaujour 2012) they are still peculiar for the production of milk, butter and cheese with high specific nutrition values and they provide a typical landscape that may renew touristic and cultural interests. However, today it looks imperative that for their conservation, especially below the tree line, they must be managed such that they remain reasonably economically pro- ductive. Both agricultural intensification and abandonment of grasslands lead to decreasing species diversity (Grootjans et al. 1996, Linusson et al. 1998, Stampfli and Zeiter 1999, Bassignana et al. 2002, Tasser and Tappeiner 2002, Dickson and Foster 2011, Samuil et al. 2013). Therefore, a trade-off between the conservation of biodiversity and economic productivity must be found and applied at large scale where it is still feasible (Török et al. 2016).

The permanent grasslands constitute a heritage that provides spontaneous gene pools "filtered by the environment" during the biogeographic history of the Earth and whose yields are used according to the needs and culture of the people who manage them. Traditionally, they were grazed or mowed. The mowed ones were treated mainly by manure; the others were left without fertilization. In the past 50 years, both mowed and grazed grasslands have also been treated with chemical fertilizers. However, notwithstanding the increased productivity (also in terms of milk and meat) due to this new practice, the grasslands did not show economic competitiveness with re- 
spect to feeding the animals with monocultural fodder crops. What could make sharp difference between these crops and the permanent grasslands is the better quality of the products of the latter and the fact that, if properly managed, permanent grasslands offer many of the so-called ecosystem services (Daily 1997, MEA 2005). It is for these reasons that the 2013 reform of the European Common Agricultural Policy (CAP) tries to support farmers willing to follow the environmentfriendly rural practices, by the so called 'green payment". More specifically, it is also suggested that governments and regions should maintain the ratio of permanent grassland area to the total Utilized Agricultural Area (UAA) according to some greening rules (Huyghe et al. 2014) (https://ec.europa. eu/agriculture/direct-support/greening_en).

This European reform encouraged us to revisit our old unpublished data, obtained by experiments of chemical fertilization on grasslands in the eighties, in order to give some useful contribution to the knowledge of the effects of fertilization on plant yield and plant diversity necessary to support the new European policy. There is a wide literature on the relationships between biodiversity and ecosystem stability and productivity so we do not want to enter into such a broad discussion that leads to the "questionable" hypothesis that the stability of ecosystems improves via the increment of biodiversity (e.g., Margalef 1957, May 1975, Tilman et al. 1996, Loreau et al. 2001, Tilman and al. 2006). Instead, with this study we want to answer the question: "What can we learn from the experiments done by chemical fertilization with NPK (Nitrogen, Phosphorus and Potassium) on the relationship between productivity (yield) and species diversity of permanent grasslands?"

There are many articles published in the so-called "grey literature" (internal reports, papers published in local journals, doctoral theses etc.) which present results of experiments made between the seventies and nineties on the effects of mineral fertilization on the yield and diversity of permanent grasslands. There are also results of many experiments done in the same period which have never been published. In this paper, we have chosen to present and discuss unpublished results of two of them, one from NE Italy and one from Slovakia. We have chosen these two experiments because we think that we can answer the above question through their comparison. They have been carried out in the eighties within the activity of a coordinated network of European Institutions dedicated to the study of the effects of mineral fertilization on European grasslands (Prins and Kessler 2014, www.europeangrassland.org) and of the Italian network project IPRA (Sarno et al. 1989). The experiment in NE Italy was carried out in Valbruna from 1978 to 1990 . The experiment of Vel'ká Lúka was set up in the western part of "Zvolenská kotlina" basin in 1961 and is still going on (Vargová et al. 2012). The approach that we have applied is based on "similarity theory" (Feoli and Orloci 2011), i.e., on the assumption that two plant communities similar from a floristic point of view should also be similar from the environmental point of view. In our context, this means that if two plots of permanent grasslands treated with different fertilizers result in significantly similar floristic combinations to belong significantly to the same cluster based on floristic similarity, then the two treatments should be considered equivalent and we can choose, among them, the one with the lowest energy cost. We think this approach is very useful because it can help to find the above mentioned trade-off in situations where the owners and farmers do not have sufficient income through the CAP measures if they would strictly operate without the use of fertilizers (MEA 2005, TEEB 2010).

\section{Materials and methods}

\section{Study areas and experimental designs}

The sites of the two case studies (Valbruna, IT) and (Vel'ká Lúka, SK) and the experimental designs are described in Table 1.

Both experiments are based on block randomization (Rand.block). In IT there are 108 plots given by four replicates for each possible combination of the values of NPK $\left(3^{3}\right.$ $=27$ ). In SK the number of plots is 20 because the combinations of NPK are fixed in five types: 1) 0 - 0 - 0 (the control); 2) 50 - 15.4 - 41.5; 3) 100 - 30.8 - 88; 4) 150 - 46.2 - 124.5; 5) $200-61.6-166 \mathrm{~kg} / \mathrm{ha}$. Climate data have been obtained from the closest meteorological station. Soil analysis was made by methods described in Jackson (1958), Black (1965), Walsh and Beaton (1973) for the IT experiment and Tjurin (1951), Schachtschabel and Köster (1959), and Egner et al. (1960) for the SK experiment.

\section{Vegetation data}

Both experiments were conducted on semi-natural permanent grasslands that according to the Braun-Blanquet approach (van der Maarel 1975) belong to the class MolinioArrhenatheretea Tüxen 1937 (Chytrý and Blažková 2007). The grassland of IT could be assigned to the association Molinietum caeruleae Koch 1926 belonging to the alliance Molinion caeruleae Koch 1926, while the grassland of SK to the association Poo-Trisetetum flavescentis Knapp ex Oberdorfer 1957 belonging to the alliance Arrhenatherion elatioris Luquet 1926 (Chytrý and Blažková 2007).

Vegetation relevés have been made in the 108 plots $(27 \times$ 4) in IT and in $20(5 \times 4)$ plots in SK corresponding to the replicates of the two experimental designs (Table 1). In the relevés, the cover value of each species was estimated by the visual method in IT and by the reduced projective dominance method (Gáborčík and Javorková 1980) in SK. In both cases, the cover values of the species have been relativized to their totals, so they range between 0 and 1 . To simplify the presentation of the relevant results, in this paper we report only on the analyses of data collected in 1985 because, at this date, the floristic composition in the experimental plots of the two sites reached a good and remarkable stability from 1981. The striking difference between the two experimental designs is that in IT the fertilizers $\mathrm{N}, \mathrm{P}$ and $\mathrm{K}$ were taken as independent variables by considering the $27\left(=3^{3}\right)$ combinations of three values of $\mathrm{N}, \mathrm{P}, \mathrm{K}$ (see Table 1) (it follows that the correlation 
Table 1. Characteristics of the sites, Valbruna (IT) and Vel'ká Lúka (SK). The three levels of NPK in IT have been combined in 27 combinations, in SK the combinations are only 5 , the control (0-0-0) and those that can be read in colums under the control.

\begin{tabular}{|c|c|c|}
\hline & IT & SK \\
\hline \multirow[t]{2}{*}{ Site coordinates } & $46^{\circ} 30^{\prime} 24 " \mathrm{~N}$ & $48^{\circ} 37^{\prime} 57^{\prime \prime} \mathrm{N}$ \\
\hline & $13^{\circ} 26^{\prime} 22^{\prime \prime} \mathrm{E}$ & $19^{\circ} 9^{\prime} 55^{\prime \prime} \mathrm{E}$ \\
\hline Altitude & 807 m.a.s.1. & 350 m.a.s.1. \\
\hline Mean daily tempeperature & $7.0^{\circ} \mathrm{C}$ & $8.2^{\circ} \mathrm{C}$ \\
\hline Sum of annual rainfall & $1348 \mathrm{~mm}$ & $757 \mathrm{~mm}$. \\
\hline Number of mowings/year & 2 & 3 \\
\hline \multicolumn{3}{|l|}{ Soil characteristics } \\
\hline Soil type & Medium-loam & Loamy-fluvisol \\
\hline $\mathrm{pH}$ in $\mathrm{KCl}$ & 7.1 & 6.03 \\
\hline Humus $(\mathrm{g} / \mathrm{kg})$ & 25.5 & 33.3 \\
\hline$N(\%)$ & 0.18 & 0.22 \\
\hline $\mathrm{P}(\mathrm{mg} / \mathrm{kg})$ & 10.11 & 6.16 \\
\hline $\mathrm{K}(\mathrm{mg} / \mathrm{kg})$ & 24.3 & 96.6 \\
\hline Experimental design & Rand. block & Rand. block \\
\hline Treatment $\mathrm{x}$ replication & $27 \times 4$ & $5 \times 4$ \\
\hline Number of plots & 108 & 20 \\
\hline Plot size & $25 \mathrm{~m}^{2}$ & $32 \mathrm{~m}^{2}$ \\
\hline Fertilization levels & \multicolumn{2}{|c|}{ Levels of nutrients $(\mathrm{kg} / \mathrm{ha})$} \\
\hline N-P-K (control) & $0-0-0$ & $0-0-0$ \\
\hline $\mathrm{N}$ & $0-150-300$ & $50-100-150-200$ \\
\hline $\mathrm{P}$ & $0-32.73-65.46$ & $15.4-30.8-46.2-61.6$ \\
\hline $\mathrm{K}$ & $0-62.26-124.51$ & $41.5-88-124.5-166$ \\
\hline
\end{tabular}

between $\mathrm{N}, \mathrm{P}, \mathrm{K}$ is 0 ), while in SK the fertilizers have been supplied in four combinations, besides the control, in which the values of the fertilizers are increasing in a perfectly correlated way (it follows that in this last case the correlation between $\mathrm{N}, \mathrm{P}$ and $\mathrm{K}$ results is equal to 1 ). As a consequence of the different experimental designs, in IT we can evaluate the effects of the single elements, the effects of the combination of the elements two by two and three by three, while in SK we can evaluate the synergistic effects of the simultaneous increases of all the three elements.

The relevés of IT have been merged into 27 "vegetation units", while the relevés of SK into five "vegetation units" corresponding to the respective different treatments. The control in both cases is considered the one without treatment. We give the list of species subdivided into grasses, legumes and forbs in Table S1 of Electronic Appendix (notwithstanding graminoids, the species of Carex, found only in Italy, have been included in the forbs to avoid another category that in any case disappeared after few years of tretaments) .

\section{Data analysis}

The "vegetation units" (VU), of both data sets were analyzed separately in the same way. They were compared by the similarity ratio function using both the percentage cover and binary data for which the similarity ratio becomes the index of Jaccard (Podani 2000). To the matrices of similarity, we applied the group average linkage cluster analysis (Podani 2000). The optimal classification was defined by the method of the evenness of the eigenvalues (Feoli et al. 2009). According to this method the higher the evenness the higher the sharpness and therefore the overall heterogeneity of the data set, in our case sets of VUs. For each vegetation unit, we have considered the following "alpha" diversity statistics: the number of species (richness), Gini-Simpson (GS) diversity index, the Shannon diversity index $(\mathrm{H})$, and the Hill number (Hill 1973) abbreviated as $\mathrm{e}^{\mathrm{H}}$; and the following "beta" diversity values: the average similarity based on the similarity ratio (SJ), the average dissimilarity DSJ (1-SJ), the average nestedness (NSJ, i.e., the average relative inclusion of one set in another set, see Urlich et al. 2009, 2012), the average nestedness resultant dissimilarity (NDSJ), and the average number of species raised to the average dissimilarity (nsp $\left.{ }^{\mathrm{DSJ}}\right)$ (Feoli 2010). Nestedness (NSJ) is calculated as the ratio of the Jaccard index (SJ) and the maximum value of the index (SJmax). The maximum is realized only if the two units have perfect similarity or complete nestedness. When the Jaccard index is replaced by the Sorensen index (SS), it is easy to demonstrate that SS/SSmax becomes the index of Simpson (1943, 1960). The nestedness resultant dissimilarity (NDSJ) is calculated by $(\mathrm{SJ} / \mathrm{SJmax})$ - $\mathrm{SJ})$ as proposed by Baselga (2010) for the index of Sorensen. To measure the correlation between the quantities of supplied fertilizers N, P, K, the species diversity statistics, and the yield we have applied the well-known correlation Pearson's coefficient (Podani 2000). For the IT data set we have applied also the partial correlation (Wessa 2016) to isolate the effects of the single nutrient on the yield and on species richness. For SK, this analysis is not possible because the doses of NPK vary in a collinear way. The yields of different treatment have been compared by the test of Duncan within a classical analysis of variance (ANOVA).

Besides using different measures of diversity the two data sets were compared by ternary plots (Podani and Schmera 2011), i.e., the one based on the relationship

$\mathrm{R}+\mathrm{D}+\mathrm{S}=1$, 
where $\mathrm{R}$ is the relativized replacement, $\mathrm{D}$ is the relativized richness difference and $\mathrm{S}$ is the Jaccard's similarity. By this comparison it is possible to put in evidence the effects of fertilization on beta-diversity between the VUs of the two grasslands (Podani and Schmera 2012, 2016).

In order to evaluate the performance of the different treatments in terms of the balance between the energy stored in the yield and the energy necessary to produce the fertilizers N, P, $\mathrm{K}$, we have transformed the tons of the dry matter of yield of each VU into MJ (Mega Joule) according to the factor (18.18) suggested by Kizeková et al. (2017) and the quantities of the fertilizers that we assume to be used in the experiments, i.e., urea, triple superphosphate (TSP), potassium chloride $(\mathrm{KCl})$ indicated as $\mathrm{N}, \mathrm{P}, \mathrm{K}$ according to the factors suggested by Ledgard et al. (2011). This transformation leads to the following values for the production of the pure elements whose quantities have been used by us (Table 1 ): $\mathrm{MJ} / \mathrm{kg} \mathrm{N}=52.02$, $\mathrm{MJ} / \mathrm{kg} \mathrm{P}=17.21$ and $\mathrm{MJ} / \mathrm{kg} \mathrm{K}=11.77$.

\section{Results}

The results of the classification of the VUs of the two sites based on similarity and cluster analysis show that both sets of them can be divided into three main clusters (Fig. 1).

The evenness of the eigenvalues of the IT similarity matrix is 0.67 , while the evenness of the similarity matrix reduced to the size of $3 \times 3$ according to 3 clusters is 0.78 . The evenness of the SK similarity matrix is 0.55 while it is 0.67 for the reduced matrix according to three clusters. Since lower evenness means more homogeneity, these evenness values prove that the treatments of SK produce a more homogeneous vegetation than the one produced by the treatments of IT. This result is confirmed and illustrated in more detail by the ternary plots based on the method suggested by Podani and Schmera (2011) (Fig. 2). In the ternary plots the point swarm is attached to the S-R side of the triangle for the experiment in IT, while all points are confined to the lower right corner in the experiment of SK. This shows that the similarity component is much higher in the latter, which leads to a higher level of nestedness as well. In the ternary plot pertaining to the
IT experiment, species replacement is much more expressed, suggesting some underlying gradient behind the flora of VUs.

Table 2 shows the description of the three clusters by the average values of the diversity statistics for both IT and SK.

a

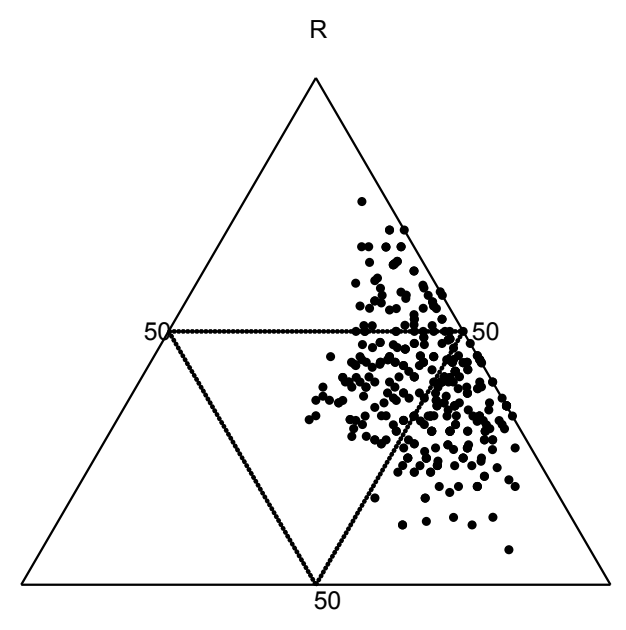

D S

b

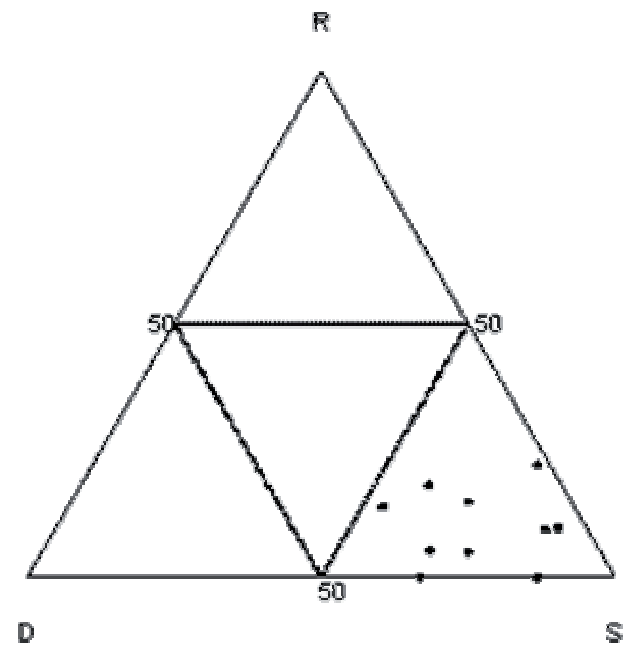

Figure 2. Ternary plots of IT (a) and SK (b) based on the method of Podani and Schmera (2011):

a

b
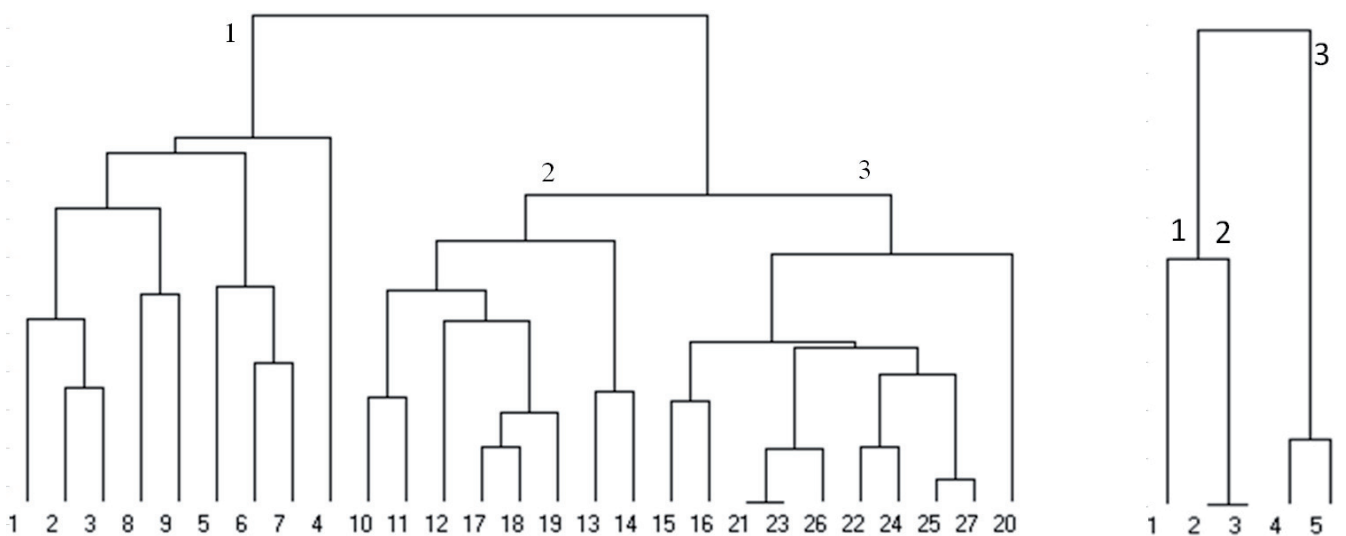

Figure 1. Dendrograms of the classification of the VUs: a. for the VUs of IT, b. for the VUs of SK. 
Table 2. Description of the three clusters obtained for IT and SK by the average values of the considered parameters. Legend to symbols: $\mathrm{N}=$ Nitrogen, $\mathrm{P}=$ Phosphorous, $\mathrm{K}=$ Potassium, $\mathrm{n}=$ number of, $\mathrm{G}=$ grasses, $\mathrm{L}=$ legumes, $\mathrm{F}=$ Forbs, Tot $=$ Total, $\mathrm{sp}=\mathrm{species}$, $\mathrm{p}=$ proportion of, cov = cover, $\mathrm{DM}=$ Dry matter, ha $=$ hectar, $\mathrm{DS}=$ dissimilarity $(1-\mathrm{SJ}), \mathrm{e}=2.781, \mathrm{H}=$ entropy of Shannon, $\mathrm{E}=$ evenness, GD $=$ Gini-Simpson diversity, $\mathrm{SJ}=$ index of Jaccard, NSJ $=$ SJ/SJmax $=$ Nestedness $($ see text). NDSJ = nestedness resultant dissimilarity.

\begin{tabular}{lcccccc}
\hline & \multicolumn{3}{c}{ IT } & & & SK \\
\hline Cluster & 1 & 2 & 3 & 1 & $2+3$ & $4+5$ \\
\hline $\mathrm{N}$ & 150 & 37.5 & 240 & 0 & 75 & 175 \\
$\mathrm{P}$ & 0 & 103.1 & 120 & 0 & 23.1 & 53.9 \\
$\mathrm{~K}$ & 75 & 84.38 & 67.5 & 0 & 62.25 & 145.3 \\
$\mathrm{n} \mathrm{G}$ & 5.444 & 8.25 & 7.8 & 11 & 13 & 10.5 \\
$\mathrm{n} \mathrm{L}$ & 5.333 & 5 & 4.3 & 6 & 4 & 2.5 \\
$\mathrm{n} \mathrm{F}$ & 20.89 & 14.5 & 13.3 & 23 & 21 & 15 \\
$\mathrm{nsp}$ & 31.67 & 27.75 & 25.4 & 40 & 38 & 28 \\
$\mathrm{G}$ p cov & 0.146 & 0.336 & 0.567 & 0.358 & 0.562 & 0.795 \\
$\mathrm{~L}$ p cov & 0.308 & 0.274 & 0.125 & 0.253 & 0.158 & 0.032 \\
$\mathrm{~F}$ p cov & 0.546 & 0.39 & 0.308 & 0.389 & 0.279 & 0.173 \\
Yield (DM) tons/ha & 3.967 & 9.05 & 9.8 & 3.57 & 6.6 & 11.32 \\
eveness(E) & 0.792 & 0.784 & 0.73 & 0.88 & 0.84 & 0.75 \\
Shannon (H) & 2.737 & 2.602 & 2.361 & 3.241 & 3.063 & 2.497 \\
$\mathrm{GD}$ & 0.902 & 0.901 & 0.848 & 0.95 & 0.936 & 0.885 \\
$\mathrm{e} \wedge \mathrm{H}$ & 15.65 & 13.41 & 10.91 & 25.52 & 21.47 & 12.05 \\
$\mathrm{SJ}$ & 0.465 & 0.534 & 0.521 & 0.743 & 0.802 & 0.758 \\
$\mathrm{DSJ}$ & 0.535 & 0.466 & 0.479 & 0.41 & 0.215 & 0.325 \\
nsp (DSJ) & 6.35 & 4.739 & 4.606 & 4.53 & 2.18 & 2.95 \\
NSJ & 0.543 & 0.603 & 0.616 & 0.857 & 0.919 & 0.932 \\
NDSJ & 0.078 & 0.069 & 0.095 & 0.114 & 0.117 & 0.174 \\
\hline
\end{tabular}

Table 3. Within and between similarity (WB) of the clusters of VUs for IT and SK; Sp = similarity based on proportional cover; $\mathrm{Sb}=\mathrm{simi}-$ larity based on binary data. Within similarities are the values in the diagonal of the matrices, the between similarities are those outside.

\begin{tabular}{|c|c|c|c|c|c|c|}
\hline \multirow[b]{3}{*}{ Cluster } & \multicolumn{6}{|c|}{ WB Sp } \\
\hline & \multicolumn{3}{|c|}{ IT } & \multicolumn{3}{|c|}{ SK } \\
\hline & 1 & 2 & 3 & 1 & 2 & 3 \\
\hline 1 & 0.500761 & 0.243034 & 0.11471 & 1 & 0.723069 & 0.264426 \\
\hline 2 & 0.243034 & 0.644073 & 0.443121 & 0.723069 & 0.981546 & 0.614988 \\
\hline \multirow[t]{3}{*}{3} & 0.11471 & 0.443121 & 0.700933 & 0.264426 & 0.614988 & 0.949234 \\
\hline & \multicolumn{6}{|c|}{$\mathrm{WB} \mathrm{Sb}$} \\
\hline & & IT & & & SK & \\
\hline Cluster & 1 & 2 & 3 & 1 & 2 & 3 \\
\hline 1 & 0.553359 & 0.407453 & 0.385991 & 1 & 0.794444 & 0.563 \\
\hline 2 & 0.407453 & 0.592613 & 0.56049 & 0.79444 & 0.853659 & 0.681 \\
\hline 3 & 0.385991 & 0.56049 & 0.567854 & 0.5629 & 0.68114 & 0.867 \\
\hline
\end{tabular}

The within and between-cluster similarities of the three IT clusters (the control is included in cluster 1) and SK are given in Table 3. Table 4 shows for the two sites the yield differences between the treatments, with the results of the Duncan's test.

The correlation ( $\mathrm{r}$ ) between the NPK and yield, according to the supplied doses, and all the other values in Table 2 is given in Table 5 on the basis of all the data. SK has only one column for NPK because the correlation between the fertilizers $\mathrm{N}, \mathrm{P}, \mathrm{K}$ is equal to 1 .

In Table A1 of the Electronic Appendix, the three clusters are described by the average proportion of the species and by their presence absence. The species are grouped in three categories: grasses $(\mathrm{G})$, legumes $(\mathrm{L})$ and forbs $(\mathrm{F})$. The species of genus Carex have been included in the category of forbs notwithstanding that they are graminoids. Sedges are very sensitive to fertilization and disappeared in the fertilized plots after few years of the experiment. From this table we can see in detail which species take advantage by the treatments and which are depressed.

In Table 6 are presented the energy costs of fertilizers $(\mathrm{MJ} / \mathrm{kg})$ and the energy stored in the yield in the three clusters of Table 2 based on the corrected conversion factors sug- gested respectively by Ledgard et al. (2011) and Kizeková et al. (2017). In this table, the control of IT has been removed from cluster 1 and showed in one independent column.

By analyzing the Figures and the Tables we can summarize the results in the following 8 main points:

1) The control treatment of IT (i.e., NPK $=0-0-0$ ) is included in cluster 1 of VUs, while it remains separated in the classification of vegetation units of SK. Table 2 shows that in both cases, IT and SK, the three clusters reveal a gradient of intensification of fertilization, along which we can see the decrement of all the parameters of diversity included the nspD, i.e., the number of species of the VUs raised to the average dissimilarity they have with the other VUs (a measure of beta diversity). This is in agreement with the results expressed by ternary plots and it means that the effects of fertilization are the reduction of richness and the heterogeneity of the grasslands, i.e., both the so called alpha and beta diversity and an increment of nestedness and of nestedness resultant dissimilarity.

2) Table 2 shows that in IT the cluster with the highest level of fertilization (with an average number of 25.4 species and the average value of $\left.n \mathrm{p}^{\mathrm{E}}=10.91\right)$ lost on the average 
Table 4. The average value of yield for each treatment and the results of the Duncan's test of the comparisons between the yields of different treatments ( $a, b, c, d, e, f$ mark the significant difference in subsequent values).

\begin{tabular}{|c|c|c|c|c|c|}
\hline \multicolumn{4}{|c|}{ IT } & \multicolumn{2}{|l|}{ SK } \\
\hline N P K & & N P K & & N P K & \\
\hline Treatment & Yield (t/ha) & Treatment & Yield (t/ha) & Treatment & Yield (t/ha) \\
\hline 122 & $10.9 \mathrm{a}$ & 010 & $8.9 \mathrm{~d}$ & $200-61.6-166$ & $12.26 \mathrm{a}$ \\
\hline 222 & $10.7 \mathrm{ab}$ & 210 & $8.7 \mathrm{~d}$ & $150-42.6-124.5$ & $10.38 \mathrm{a}$ \\
\hline 211 & $10.6 \mathrm{ac}$ & 112 & $8.7 \mathrm{~d}$ & $100-30.8-88$ & $6.26 \mathrm{~b}$ \\
\hline 212 & $9.9 \mathrm{ad}$ & 110 & $8.7 \mathrm{~d}$ & $50-15.4-41.5$ & $6.94 \mathrm{~b}$ \\
\hline 221 & $9.9 \mathrm{ad}$ & 201 & $4.9 \mathrm{e}$ & $0-0-0$ & $3.57 \mathrm{c}$ \\
\hline 121 & $9.7 \mathrm{bd}$ & 102 & $4.2 \mathrm{e}$ & & \\
\hline 220 & $9.5 \mathrm{bd}$ & 202 & $4.2 \mathrm{ef}$ & & \\
\hline 120 & $9.4 \mathrm{bd}$ & 101 & $4.1 \mathrm{ef}$ & & \\
\hline 111 & $9.4 \mathrm{bd}$ & 200 & $3.9 \mathrm{ef}$ & & \\
\hline 022 & $9.4 \mathrm{bd}$ & 000 & $3.9 \mathrm{ef}$ & & \\
\hline 021 & $9.2 \mathrm{~cd}$ & 100 & $3.9 \mathrm{ef}$ & & \\
\hline 012 & $9.0 \mathrm{~d}$ & 002 & $3.7 \mathrm{ef}$ & & \\
\hline 011 & $8.9 \mathrm{~d}$ & 001 & $2.9 \mathrm{ef}$ & & \\
\hline 020 & $8.9 \mathrm{~d}$ & & & & \\
\hline Average yield & 7.6 & & & Average yield & 7.88 \\
\hline $\begin{array}{l}\mathrm{N}, 1: 150 \mathrm{~kg}, 2 \\
\mathrm{P}, 1: 32.73,2: 6 \\
\mathrm{~K}, 1: 62.26,2:\end{array}$ & & & & & \\
\hline
\end{tabular}

Table 5. Correlation coefficients (r) between fertilizers NPK the yield and the chosen statistics of diversity. Numbers in bold indicate significant correlations. For symbols, see Table 2.

\begin{tabular}{|c|c|c|c|c|c|c|}
\hline \multicolumn{5}{|c|}{ IT } & \multicolumn{2}{|c|}{ SK } \\
\hline & $\mathrm{N}$ & $\mathrm{P}$ & $\mathrm{K}$ & Yield & NPK & Yield \\
\hline $\mathrm{N}$ & 1 & 0 & 0 & 0.127 & 1 & 0.955 \\
\hline $\mathrm{P}$ & 0 & 1 & 0 & 0.882 & 1 & 0.955 \\
\hline $\mathrm{K}$ & 0 & 0 & 1 & 0.083 & 1 & 0.955 \\
\hline n Grasses & -0.21 & 0.459 & 0 & 0.517 & -0.312 & -0.487 \\
\hline n Legumes & -0.36 & -0.306 & -0.050 & -0.443 & -0.769 & -0.907 \\
\hline n Forbs & -0.10 & -0.733 & -0.022 & -0.833 & -0.979 & -0.956 \\
\hline nsp & -0.29 & -0.589 & -0.035 & -0.695 & -0.906 & -0.971 \\
\hline G pcov & 0.458 & 0.691 & -0.106 & 0.806 & 0.923 & 0.962 \\
\hline L p cov & -0.66 & -0.389 & -0.107 & -0.556 & -0.946 & -0.983 \\
\hline F p cov & -0.11 & -0.741 & 0.272 & -0.767 & -0.889 & -0.930 \\
\hline Yield (DM) tons/ha & 0.128 & 0.882 & 0.083 & 1 & 0.955 & 1 \\
\hline eveness (E) & -0.37 & -0.361 & 0.050 & -0.375 & -0.906 & -0.944 \\
\hline Shannon $(\mathrm{H})$ & -0.37 & -0.488 & 0.020 & -0.540 & -0.916 & -0.972 \\
\hline GD & -0.49 & -0.361 & 0.010 & -0.406 & -0.867 & -0.935 \\
\hline $\mathrm{e}^{\wedge} \mathrm{H}$ & -0.29 & -0.526 & 0.024 & -0.583 & -0.918 & -0.979 \\
\hline SJ & -0.35 & 0.544 & 0.091 & $\mathbf{0 . 5 9 7}$ & 0.113 & 0.062 \\
\hline DSJ & 0.348 & -0.544 & -0.091 & -0.597 & -0.113 & -0.062 \\
\hline$n s p^{(D S J)}$ & 0.162 & -0.691 & -0.075 & -0.762 & -0.401 & -0.366 \\
\hline NSJ & -0.13 & 0.594 & 0.097 & 0.626 & 0.864 & 0.826 \\
\hline NDSJ & 0.407 & 0.223 & 0.031 & 0.188 & 0.860 & 0.842 \\
\hline $\mathrm{N}$ & 1 & 0 & 0 & 0.127 & 1 & 0.955 \\
\hline $\mathrm{P}$ & 0 & 1 & 0 & 0.882 & 1 & 0.955 \\
\hline
\end{tabular}

Table 6. Energetic costs to produce the fertilizers and the energy available from the forage both in $\mathrm{MJ} / \mathrm{kg}$. Legend to symbols $\mathrm{N}=$ Nitrogen, $\mathrm{P}=$ Phosphorus, $\mathrm{K}=$ Potassium, $\mathrm{DM}=$ Dry Matter.

\begin{tabular}{|c|c|c|c|c|c|c|c|}
\hline & \multicolumn{4}{|c|}{ IT } & \multicolumn{3}{|c|}{ SK } \\
\hline & \multicolumn{4}{|c|}{ Cluster } & \multicolumn{3}{|c|}{ Cluster } \\
\hline & 1 & 2 & 3 & control & 1 & $2+3$ & $4+5$ \\
\hline & \multicolumn{4}{|c|}{ Fertilizers kg/ha $(\mathrm{N}-\mathrm{P}-\mathrm{K})$} & \multicolumn{3}{|c|}{ Fertilizers kg/ha $(\mathrm{N}-\mathrm{P}-\mathrm{K})$} \\
\hline & $150-0-75$ & $37-103-84$ & $240-120-67$ & $0-0-0$ & $0-0-0$ & $75-23-62$ & $175-53-145$ \\
\hline Yield kg/ha DM & 3970 & 9050 & 9800 & 3900 & 3570 & 6600 & 11320 \\
\hline $\mathrm{MJ} / \mathrm{ha} \mathrm{N}$ & 7803 & 1951 & 12485 & 0 & 0 & 3902 & 9104 \\
\hline $\mathrm{MJ} / \mathrm{ha} \mathrm{P}$ & 0 & 1775 & 2065 & 0 & 0 & 398 & 928 \\
\hline $\mathrm{MJ} / \mathrm{ha} \mathrm{K}$ & 883 & 993 & 794 & 0 & 0 & 733 & 1710 \\
\hline $\begin{array}{l}\text { Total MJ/ha } \\
\text { N - P - K }\end{array}$ & 8686 & 4719 & 15344 & 0 & 0 & 5032 & 11741 \\
\hline $\mathrm{MJ} / \mathrm{ha}$ by yield & 72120 & 164529 & 178164 & 70902 & 64903 & 119988 & 205798 \\
\hline MJ benefit & 63434 & 159810 & 162820 & 70902 & 64903 & 114956 & 194057 \\
\hline
\end{tabular}


seven species with respect the control (with an average of 31.76 species and $\left.\mathrm{nsp}^{\mathrm{E}}=15.65\right)$, while in $\mathrm{SK}$ the cluster with the highest level of fertilization lost on the average 12 species (40 - 28). The ratio between the average species number and the average $\mathrm{nsp}^{\mathrm{E}}\left(\mathrm{e}^{\mathrm{H}}\right)$ indicated again that in relative terms the highest fertilization of SK (ratio $=2.32$ ) reduces the species diversity (as combination richness-evenness) more than the highest fertilization in IT (ratio $=2.01)$.

3 ) If we consider the total number of species per cluster, as given in Table S1, in IT 16 species disappeared in the VUs with the highest fertilization with respect to the control, while 10 new species appeared. The total negative balance is only of six species. In SK, 12 species were lost while 4 were gained. The total negative balance is eight. It is to be emphasized that all the 26 species of IT and all the 16 in SK are widespread in European grasslands and none of them is in the list of threatened species or considered a weed (Poldini 1991).

4) The average dissimilarity (average DS in Table 2) of the VUs in the clusters with all the other VUs, indicates that the most dissimilar VUs are the less fertilized ones followed by the highly fertilized VUs. This is true for IT and SK. In both cases, the cluster with intermediate fertilization has VUs that on average are more similar to the other VUs. Note that the VUs of SK have a between similarity higher than those of IT. This result proves that the decrement of alpha diversity produces an increment of homogeneity of VUs, i.e., a decrement of beta diversity.

5 ) It is clear from Table 3 that the similarity within and between the clusters in IT (if we exclude cluster 1, that includes the control) are lower than those of SK. The similarity within-between clusters, obtained on cover data $(\mathrm{Sp})$, in terms of binary data $(\mathrm{Sb}=$ floristic similarity) decreases in both cases (IT and SK) when we consider the within-cluster similarity of the cluster with the highest fertilization. This means that fertilization produces more similarity in the pattern of proportions than in the pattern of floristic composition.

In the case of IT, the maximum similarity of the control is with the VU fertilized only with $\mathrm{K}$ and the minimal similarity is with the one fertilized with the maximum values of $\mathrm{N}$ and $\mathrm{P}$.

6) From Table 4 we can observe that in IT the highest yields were obtained by the treatments in which $\mathrm{N}$ and $\mathrm{P}$ were applied in combination, while $\mathrm{K}$ appears to have no significant effect. P is shown to have stronger effect than N. All treatments with $\mathrm{P}$ without $\mathrm{N}$ performed better than treatments without $\mathrm{P}$. The distribution of $\mathrm{N}$ without $\mathrm{P}$ had no effect and the production is at the same levels of the control. In the SK experiment, there is a linear growth of production at increasing doses of $\mathrm{N}, \mathrm{P}$ and $\mathrm{K}$. Nevertheless, the differences of yields between the plots with lower doses of $\mathrm{N}$ ( 50 and 100 $\mathrm{kg}), \mathrm{P}(15.4 \mathrm{~kg}$ and $30.8 \mathrm{~kg})$ and $\mathrm{K}(41.5 \mathrm{~kg}$ and $88 \mathrm{~kg})$ are not significant ( $6.94 \mathrm{t} / \mathrm{ha}$ vs. $6.26 \mathrm{t} / \mathrm{ha}$ of $\mathrm{DM})$. The average yields of all treatments in the two sites were very similar $(7.60 \mathrm{t} /$ ha in IT vs. $7.88 \mathrm{t} / \mathrm{ha}$ in SK). In both cases, the yields of all treatments were significantly higher than the yields obtained by the controls.

To the loss of alpha and beta species diversity, as testified by all the statistics used, there is a corresponding gain of yield, in fact it improves 2.51 times in IT while 3.17 times in SK. The gain in yield for species loss is lower in SK than in IT, respectively $3.17 / 12=0.26$ versus $2.51 / 7=0.35$ i.e., to each species lost the gain is 0.26 in SK and 0.35 in IT. However, since in both cases we are not going to lose endemic and/or rare species, but species that are with wide distribution the choice between different treatments is only a matter of economic convenience.

7) Table 5, showing the correlation between all the variables considered in Table 2, confirms the results presented in that table. It is clear that the fertilization like that of SK, i.e., a linear increment of all the three nutrients, significantly decreases all the diversity values, except the average similarity that actually increases, while it increases significantly the nestedness (SJ/SJmax) and therefore the nestedness resultant dissimilarity (NDSJ) confirming again the results showed by the ternary plots. In contrast it produces a strong increment of yield due mainly to grasses ( $\mathrm{G}$ p cov in Table 2), while legumes and forbs are decreasing in number and in their cover. The situation of IT is more complicated: Nitrogen significantly decreases both the abundance and the richness of legumes and enhances the abundance of the grasses, it does not influence any diversity statistic, but causes an increment of dominance (the Gini-Simpson diversity is significantly negatively correlated with $\mathrm{N}$ ) certainly due to the increment of the cover of grasses, that leads to an increment of nestedness resultant dissimilarity (Table 2). Phosphorus shows a more striking effect. It enhances significantly the number and the cover of species of grasses, the yield, the average similarity and nestedness (these last two are significantly correlated, $\mathrm{r}=0.88$ ) and decreases significantly all the diversity values excluding the evenness, the index of Gini-Simpson and the nestedness resultant dissimilarity. This means that the grasses, thanks to the increment of $\mathrm{P}$ are creating a grassland community with higher evenness, but with less species. Potassium shows no significant effects to any of the diversity measures. The partial correlation ( $\mathrm{r}$ x, $\mathrm{y} \mid \mathrm{z})$ between $\mathrm{P}(\mathrm{x})$ and the yield (y) by removing the effect of $\mathrm{N}(\mathrm{z})$, remains practically the same ( 0.88 to 0.89$)$ while for the number of species ( $\mathrm{rx}, \mathrm{y} \mid \mathrm{z})$ increases negatively from -0.58 to -0.62 . This means that $\mathrm{N}$, if associated with $\mathrm{P}$ would guarantee a better level of species diversity.

8) Concerning the benefits in terms of energy (Table 6), in IT the vegetation units with the higher fertilization level improved with respect the control 2.29 times, while in SK 2.99 times. In IT the cluster corresponding to an intermediate fertilization lost four species while improved the yield of 2.28 times. In SK this cluster lost only 2 species while improved the yield 1.94 times.

\section{Discussion}

The decline of permanent grasslands was mostly due to the production of annual crops and fodder maize that were, without doubt, more remunerative. A strong conversion to modern agricultural practices is present both in Italy and Slovakia. However, the new European policy is opening a new hope for the people living mainly on grassland resources that are willing to continue to produce their products in tradi- 
tional way, maintaining the traditional high quality. It is clear from our study, based on similarity theory and the extensive application of the similarity concept and formulas (the diversity measures are in fact certain types of similarity-dissimilarity formulas), that, notwithstanding the implicit imprecision and uncertainty of the data and results, grasslands or more precisely semi-natural grasslands as in our case, if properly managed may improve their yield in a considerable way by chemical fertilizers, without losing much in species diversity and with evident gain in energetic balance. From Table 6 it is clear that the fertilization can rise the yield of 2-3 times, and since the data are aggregated by clusters obtained by similarity between species combinations it is clear that different kind of fertilization may produce more or less the same changes in species composition. For example, the IT experiment would suggest that the supply of $\mathrm{K}$ in the condition of the soil on which the experiment was done is useless and also that the supply of a light quantity of $\mathrm{N}$ together with $\mathrm{P}$ would preserve the diversity that high values of the $\mathrm{P}$ would suppress. The results of the SK experiment show that the fertilization levels of treatment 2 versus treatment 3 as well as the treatment 4 versus 5 , both in terms of species composition and in terms of yield do not produce significant difference, while there is significant difference between these treatments, i.e., $2+3$ versus $4+5$ and both these two versus the control. These results are relevant since they suggest that it would be possible to choose among many possible treatments the least expensive and polluting combination of $\mathrm{N}, \mathrm{P}$ and $\mathrm{K}$ from those that, according to the species combinations of the corresponding relevés, are assigned to the same cluster. Therefore, it is very important to maintain active experiments like those illustrated in this paper since by their results a trade-off between fertilization and biodiversity conservation can be easily found. It is clear that it is not compulsory to fertilize all the available areas of permanent grasslands, some unfertilized "strips" can be easily left as biodiversity conservation "spots", without compromising much the income of the farmers. However, it must be specified that, where threatened species are present, it is obvious that other strategies must be adopted and probably chemical fertilizers should be avoided. We let economists do the computations of the economic aspects in light of the new European policy and of the results of this kind of experiments.

\section{Conclusions}

The conclusions of this paper may be summarized as follows:

- Well-balanced NPK mineral fertilization has a positive effect on yields and unimportant negative effects on biodiversity conservation. The exclusive use of $\mathrm{N}$ may have no effects on increasing the yield but negative effects on biodiversity.

- All fertilizer should be applied according to the requirements based upon soil analysis and the removal of NPK should be replaced to maintain soil levels and the botanical composition of the grassland.
- The uses of cluster analysis based on similarity theory allowed to group, on the basis of species combinations, different treatments of fertilization that actually have more or less the same effects in terms of species diversity. These results have paramount importance for managing the grasslands with the aim to conserve biodiversity.

- The use of different statistics to measure species diversity of grasslands under different fertilization treatments is able to put in evidence different patterns of species abundance and species combinations associated to the treatments.

- The experimentation on the effects of chemical fertilizers on the floristic composition of grasslands and on production is essential for planning their management in light of the new European directives.

Acknowledgments: We want to thank Dr. P. Nassimbeni and doc. Ing. O. Tomka, CSc. Past Directors of the Italian and Slovak research Institutes for having made possible the set-up of the Italian and Slovak experiments. Sincere thanks to an anonymous referee, J. Podani and prof. L. Poldini for reading and commenting the text.

\section{References}

Baselga, A. 2010. Partitioning the turnover and nestedness components of beta diversity. Global Ecol. Biogeogr. 19:134-143.

Bassignana, M., F. Bozzo, F. Gusmeroli, F. Kasal, A. Ligabue, M. Orlandi, D. and G. Parente. 2002. Specific biodiversity in alpine meadows at different degree of utilisation. Grassl. Sci. Eur. 7:1010-1011.

Black, C.A. (ed.) 1965. Methods of Soil Analysis. American Society of Agronomy, Madison, WI, USA.

Dickson, T.L. and B.L. Foster. 2011. Fertilization decreases plant biodiversity even when light is not limiting. Ecol. Lett. 14:380-388.

Chytrý, M. and D. Blažková. 2007. TD Molinio-Arrhenatheretea Tüxen 1937. In: Chytrý M. (ed.), Vegetace České republiky. 1. Travinná a keřičková vegetace [Vegetation of the Czech Republic. 1. Grassland and Heathland Vegetation]. Academia, Praha. pp. 166-168.

Daily, G.C. 1997. Nature's Services: Societal Dependence on Natural Ecosystems. Island Press, Washington.

Dengler J., M. Janišová, P. Török and C. Wellstein. 2014. Biodiversity of Palaearctic grasslands: a synthesis. Agric. Ecosyst. Environ. 182:1-14

Egner, H., H. Riehm and W.R. Domingo. 1960. Untersuchungen über die chemische Bodenanalyse als Grundlage für die Beurteilung des Nahrstoff-zustandes der Boden. II. K. Lantbrhogsk. Annlr. 20:199-216.

Feoli, E. 2010. Heath species and heathlands of Italy: an analysis of their relationships under the perspective of climate change based on the description of habitats used for the project "Carta della Natura" (Italian Map of Nature). Ecol. Quest. 12:161-170.

Feoli, E., L. Gallizia Vuerich, P. Ganis and Z. Woldu. 2009. A classificatory approach integrating fuzzy set theory and permutation techniques for land cover analysis: a case study on a degrading area of the Rift Valley (Ethiopia). Community Ecol. 10:53-64. 
Feoli, E. and L. Orlóci. 2011. Can similarity theory contribute to the development of a general theory of the plant community? Community Ecol. 12:135-141.

Gáborčík, N. and A. Javorková. 1980. Dynamika narastania pratocenóz vrátane základných produkčných procesov. [Growth dynamics of pratocenoses, including basic production processes]. Final report. Grassland Research Institute, Banská Bystrica, Slovakia.

Gaujour, E., B. Amiaud, C. Mignolet and S. Plantureux. 2012. Factors and processes affecting plant biodiversity in permanent grasslands. A review. Agron. Sustain. Dev. 32:113-160.

Grootjans, A, L. Fresco, C.C. de Leeuw and P. Schipper. 1996. Degeneration of species-rich Calthion palustris hay meadows: some considerations on the community concept. J. Veg. Sci. 7:185-194.

Habel, J.C., J. Dengler, M. Janišová, P. Török, C. Wellstein and M. Wiezik. 2013. European grassland ecosystems: Threatened hotspots of biodiversity. Biodivers. Conserv. 22:2131-2138.

Härdtle, W., B. Redecker, T. Assmann and H. Meyer. 2006. Vegetation responses to environmental conditions in floodplain grasslands. Prerequisites for preserving plant species diversity. Basic Appl. Ecol. 7:280-288.

Hill, M.O. 1973. Diversity and evenness: a unifying notation and its consequences. Ecology 54:427-432.

Hobbs, R.J. and L.F. Huenneke. 1992. Disturbance, diversity and invasive: Implication for conservation. Conserv. Biol. 6:324-337.

Huyghe C., A. De Vliegher, B. van Gils and A. Peeters. 2014. Grasslands and Herbivore Production in Europe and Effects of Common Policies. Quae editions, Versailles.

Jackson, M.L. 1958. Soil Chemical Analysis. Prentice Hall, Inc., Englewood Cliffs, NJ, USA.

Jean-Vasile, A., A. Turek Rahoveanu, J. Subic and D. Dusmanescu. (eds.) 2013. Sustainable Technologies, Policies, and Constraints in the Green Economy. IGI Global, Hershey, PA, USA.

Kemp, D.R., H. Xiangyang, D.L. Michalk, H. Fujiang, W. Jianping, and Z. Yingjung. 2013. Innovative grassland management systems for environmental and livelihood benefits. Proc. Natl. Acad. Sci. USA 110:8369-8374.

Kizeková, M., A. Hopkins, R. Kanianska, J. Makovníková, Š. Polák and B. Pálka. 2017. Changes in the area of permanent grasslands and its implications for the provision of bioenergy: Slovakia as a case study. Grass Forage Sci., doi: 10.1111/gfs.12333

Ledgard, S.F., M. Boyes and F. Brentrup. 2011. Life cycle assessment of local and omported fertilizers used on New Zealand farms. In: L.D. Currie and C.L. Christensen (eds.), Adding to the Knowledge Base for the Nutrient Manager. Fertilizer and Lime Research Centre, Massey University, Palmerston North, New Zealand. pp. 1-13.

Linusson, A., G. Berlin and E. Olsson. 1998. Reduced community diversity in semi-natural meadows in southern Sweden, 19651990. Plant Ecol. 136:77-94.

Loreau, M., S. Naeem, P. Inchausti, J. Bengtsoon, J.P. Grime, A. Hector, D.U. Hooper, M.A. Huston, D., Raffaelli, B., Schmid, D. Tilman and D.A. Wardle. 2001. Biodiversity and ecosystem functioning: Current knowledge and future challenges. Science 294:804-808.

Margalef, R. 1957. La teoria de la informacion en ecologia. Mem Real Acad. Cienc. Artes Barcelona 32:373-449.

May, R.M. 1975. Patterns of species abundance and diversity. In M.L. Cody and J.M. Diamond (eds.), Ecology and Evolution of Communities. Harvard University Press, Cambridge, MA. pp. 81-120.
Millennium Ecosystem Assessment (MEA). 2005. Ecosystems and Human Well-being: Synthesis. Island Press, Washington DC.

Nábrádi, A. 2004. The economic value of grassland products. Appl. Studies in Agribusiness and Commerce. Agroinform Publishing House. Budapest. Scientific papers. 19-28.

Pignatti, S. 1982. Flora d'Italia. Edagricole, Bologna.

Podani, J. 2000. Introduction to the Exploration of Multivariate Biological Data. Backhuys Publishing, Leiden, The Netherlands.

Podani, J. and D. Schmera. 2011. A new conceptual and methodological framework for exploring and explaining pattern in presenceabsence data. Oikos 120:1625-1638.

Podani, J. and D. Schmera. 2012. A comparative evaluation of pairwise nestedness measures. Ecography 35:889-900.

Podani, J. and D. Schmera. 2016. Once again on the components of pairwise beta diversity. Ecol. Inform. 32:63-68.

Poldini L. 1991. Atlante corologico delle specie vascolari nel FriuliVenezia Giulia. Regione Autonoma Friuli Venezia Giula and University of Trieste, Udine.

Poldini, L., G. Sburlino, G. Buffa and M. Vidali. 2011. Correlations among biodiversity, biomass and other plant community parameters using the phytosociological approach: A case study from the south-eastern Alps. Plant Biosyst. 145:131-140.

Prins, W. and W. Kessler. 2014. The European Grassland Federation at 50: past, present and future. Grassl. Sci. Eu. 19:3-11.

Samuil, C., V. Vintu, C. Sirbu and M. Stavarache. 2013. Influence of fertilizers on the biodiversity of seminatural grassland in the Eastern Carpathians. Not. Bot. Hortic. Agrobot. 41:195-200.

Sarno, R., P. Talamucci, A. Cavallero and L. Sringi. 1989. Distribuzione della produzione dei pascoli in ambienti marginali italiani. Guida alla valutazione della produttività. Progetto finalizzato CNR-IPRA Aree Marginali. Arti Grafiche Ed., Palermo.

Schachtschabel, P. and W. Köster 1959. Chemische Untersuchungen an Marchen, 3. Kaliumfixierung und Kaliumnachlieferung. Pflanzenernchr. Düng. 89:148-159.

Simpson, G.G. 1943. Mammals and the nature of continents. Am. J. Sci. 241:1-31.

Simpson, G.G. 1960. Notes on the measurement of faunal resemblance. Am. J. Sci. 258:300-311.

Stampfli, A. and M. Zeiter. 1999. Plant species decline due to abandonment of meadows cannot easily be reversed by mowing. A case study from the Southern Alps. J. Veg. Sci. 10:151-164.

Tasser, E. and U. Tappainer. 2002. Impact of land use changes on mountain vegetation. Appl. Veg. Sci. 5:173-184.

TEEB. 2010. The Economics of Ecosystems and Biodiversity: Ecological and Economic Foundations. Pushpam Kuman, Earthscan, London and Washington.

Tilman, D., D. Wedin and J. Knops. 1996. Productivity and sustainability influenced by biodiversity in grassland ecosystems. Nature 379:718-720.

Tilman D., P.B. Reich and J.M.H. Knops. 2006. Biodiversity and ecosystem stability in a decade-long grassland experiment. Nature 441:629-632.

Tjurin, I.V. 1951. Several results of study comparing humus composition in USSR soils Trudy Počvenogo Instituta 38:22-32.

Török P., N. Hölzel, R. van Diggelen and S. Tischew. 2016. Grazing in European open landscapes: How to reconcile sustainable land management and biodiversity conservation? Agric. Ecosyst. Environ. 234:1-4.

Ulrich, W. and M. Almeida-Neto. 2012. On the meanings of nestedness: back to the basics. Ecography 35:1-7. 
Ulrich, W., M. Almeida-Neto and N. Gotelli. 2009. A consumer's guide to nestedness analysis. Oikos 118:3-17.

van der Maarel, E. 1975. The Braun-Blanquet approach in perspective. Vegetatio 30:213-219.

Walsh, L.M. and J.O. Beaton. (eds.) 1973. Soil Testing and Plant Analysis. Soil Science Society of America, Madison, WI, USA.

Vargová, V., Z. Kovačiková and M. Michalec. 2012. Effects of rates and nutrient ratios on production and quality of phytomass at fertiliser application to an alluvial meadow. Agriculture 58:1-10.

Wessa P. 2016. Partial Correlation (v1.0.7) in Free Statistics Software (v1.2.1), Office for Research Development and Education. http:// www.wessa.net/rwasp_partialcorrelation.wasp/
Web sites

https:/ec.europa.eu/agriculture/direct-support/greening_en

www.europeangrassland.org

Received October 18, 2017

Revised December 4, 2017 Accepted December 26, 2017

\section{Electronic Appendix}

Table A1. List of species and description of the 3 clusters of VUs by proportion of cover values and by binary data of the species.

The file may be downloaded from www.akademiai.com. 